\title{
Microsurgery with or without Neuroendoscopy in Petroclival Meningiomas
}

\author{
Nöroendoskopi ile veya Olmadan Petroklival Menenjiyomlarda \\ Mikrocerrabi
}

Qing-Jiu ZHOU ${ }^{1}$, Bo LIU ${ }^{1}$, Dangmuren-Jiafu GENG ${ }^{1}$, Qiang FU ${ }^{1}$, Xiao-Jiang CHENG ${ }^{1}$, Kaheerman KADEER ${ }^{1}$, Guo-Jia DU ${ }^{1}$, Yong-Xin WANG ${ }^{1}$, Xin-Ping LUAN ${ }^{2}$

${ }^{1}$ The First Affiliated Hospital of Xinjiang Medical University, Department of Neurosurgery,Urumqi, China

${ }^{2}$ The Second Affiliated Hospital of Xinjiang Medical University, Department of Neurosurgery, Urumqi, China

Corresponding Author: Dangmuren-Jiafu GENG / E-mail: xinpingluan@126.com

\begin{abstract}
AIM: This study aimed to investigate the operative procedure for neuroendoscope-assisted microscopic resection of petroclival meningioma to improve prognosis.

MATERIAL and METHODS: Twelve patients with petroclival meningioma who had undergone neuroendoscope-assisted microscopic resection at the Department of Neurosurgery, First Affiliated Hospital of Xinjiang Medical University were selected. In addition, 12 patients with petroclival meningioma who had undergone microscopic surgery were used as control. Clinical data from the 24 cases of petroclival meningioma were analyzed.

RESULTS: For the neuroendoscope-assisted group, six, five, and one cases were respectively subjected to total resection, subtotal resection, and most resection. For the microscopic surgery group, two, three, and seven cases were respectively subjected to total resection, subtotal resection, and most resection. Both the total and subtotal resection rates of petroclival meningioma in the neuroendoscope-assisted group were significantly higher than those in the microscopic surgery group $(p<0.05)$. No difference was observed for short-term and long-term complications ( $p>0.05$ ) between the two groups.
\end{abstract}

CONCLUSION: Neuroendoscope-assisted microscopic resection for petroclival meningioma can improve the total and subtotal resection rates of the tumor. Moreover, this method does not increase postoperative short-term and long-term complications.

KEYWORDS: Petroclival meningioma, Microsurgical operation, Neuroendoscopy

Öz

AMAÇ: Çalışma daha iyi bir prognoz sağlamak üzere petroklival menenjiyomun nöroendoskop yardımlı mikroskopik rezeksiyonu için cerrahi işlemi incelemeyi hedefliyordu.

YÖNTEM ve GEREÇLER: Petroklival menenjiyomu olan ve Xinjiang Tıp Fakültesi'nin Birinci Yan Hastanesi'nde nöroendoskop yardımıyla mikroskopik rezeksiyon yapılmış 12 hasta seçildi. Ayrıca mikroskopik cerrahi yapılmış petroklival menenjiyomlu 12 hasta kontrol olarak kullanıldı. 24 petroklival menenjiyom olgusundan klinik veriler analiz edildi.

BULGULAR: Nöroendoskop yardımlı grupta sırasıyla altı, beş, ve bir olguda total rezeksiyon, subtotal rezeksiyon ve maksimum rezeksiyon yapıldı. Mikroskopik cerrahi grubunda sırasıyla iki, üç ve yedi olguda total rezeksiyon, subtotal rezeksiyon ve maksimum rezeksiyon yapıldı. Nöroendoskop yardımlı grupta petroklival menenjiyom için hem total hem subtotal rezeksiyon oranları mikroskopik cerrahi grubundan önemli ölçüde daha yüksekti $(p<0,05)$. Gruplar arasında kısa dönemli ve uzun dönemli komplikasyonlar bakımından bir fark görülmedi ( $p>0,05)$.

SONUÇ: Petroklival menenjiyom için nöroendoskop yardımlı mikroskopik rezeksiyon, tümörün total ve subtotal rezeksiyon oranlarını arttırabilir. Ayrıca bu yöntem postoperatif kısa dönemli ve uzun dönemli komplikasyonları artırmaz.

ANAHTAR SÖZCÜKLER: Petroklival menenjiyom, Mikroşirürji ameliyatı, Nöroendoskopi

\section{INTRODUCTION}

Petroclival meningioma refers to meningioma located in the upper $2 / 3$ of the clivus of the posterior cranial fossa and in the petroclival fissure within the internal acoustic meatus (16). Given the complex anatomic relationships occurring in the petroclival region, important cranial nerves such as the oculomotor, trochlear, abducens, trifacial, facial, and posterior cranial nerves, as well as essential blood vessels such as the basilar, posterior cerebral, and superior cerebellar arteries exist in this region. The cavernous sinus, brain stem, and internal auditory canal are respectively in front of, behind, and at the lateral side of the tumor. Thus, removing a petroclival meningioma is always difficult in skull base surgery $(4,5,10$, 12-18).

Endoscopic neurosurgery has rapidly developed in recent years and has become an indispensable technique in modern 
neurosurgery. Neuroendoscopy has had a unique promotive function in the development of skull base, ventricle, spinal cord, and spine surgeries (21). Skull base surgery is also being developed as a minimally invasive procedure. At present, numerous studies have been conducted on skull base neuroendoscopy of hypophysomas, chordomas, and saddle area anatomy $(2,3,6,8,9)$. Based on the minimally invasive skull base approach, neuroendoscopy was included in petroclival meningioma operations in this study. During microscopic surgery, neuroendoscopy is used auxiliarily to cut off petroclival meningioma.

In this study, 12 patients with petroclival meningioma who had undergone neuroendoscope-assisted microscopic resection at the Department of Neurosurgery, First Affiliated Hospital of Xinjiang Medical University from January 2010 to January 2012 were selected. In addition, 12 patients with comparative clinical data who had undergone microscopic surgery of petroclival meningioma from January 2005 to January 2010 were used as control. Their operative procedures and experiences were analyzed and summarized.

\section{MATERIAL and METHODS}

\section{Objects}

A retrospective analysis was conducted on the clinical data of 12 cases with petroclival meningioma who had undergone neuroendoscope-assisted microscopic resection at the Department of Neurosurgery, First Affiliated Hospital of Xinjiang Medical University from January 2010 to January 2012 (the neuroendoscope-assisted group). The comparative clinical data of 12 cases who had undergone microscopic surgery of petroclival meningioma from January 2005 to January 2010 (the microscopic surgery group) were used as control. This study was conducted in accordance with the declaration of Helsinki. This study was conducted with approval from the Ethics Committee of Xinjiang Medical University. Written informed consent was obtained from all participants.

\section{General Data}

The neuroendoscope-assisted group comprised 12 cases: 4 male and 8 female patients. Their ages ranged from 21 years to 70 years, and the mean age was 42.4 years. The disease duration ranged from two weeks to 11 years, and the mean duration was 2.8 years. The microscopic surgery group comprised 12 cases: 5 male and 7 female patients. Their ages ranged from 19 years to 71 years, and the mean age was 43.6 years. The disease duration ranged from 8 years to 11 years, and the mean duration was 2.6 years.

\section{Clinical Manifestations and Signs}

The two groups had a total of 24 cases with petroclival meningioma: 16 cases had headache and dizziness, 14 cases walking unsteadily, 8 cases unilateral limb weakness, 9 cases diplopia, 4 cases tic douloureux, 10 cases facial numbness, 9 cases tinnitus at the affected side, and 6 cases hearing loss.
Physical examinations detected cranial nerve deficiency symptoms including 16 cases of cranial nerve pair V, VI, VII, and VIII disorders. Among them, eight cases had multiple cranial nerve palsies, seven unilateral pyramidal signs, eight cervical rigidity and compulsive head, and five had half-body sensory disorders.

\section{Imaging Examination}

Plain and enhanced magnetic resonance imaging (MRI) examinations were conducted on all patients. Tumor diameters in the neuroendoscope-assisted group ranged from $2.0 \mathrm{~cm}$ to $5.4 \mathrm{~cm}$, whereas those in the microscopic surgery group ranged from $2.1 \mathrm{~cm}$ to $5.4 \mathrm{~cm}$. Based on the criteria presented by Natarajan et al. (16), tumors were classified in terms of maximum diameter into the mini type $(<1.0 \mathrm{~cm})$, middle type $(1.0 \mathrm{~cm}$ to $2.4 \mathrm{~cm})$, large type $(2.5 \mathrm{~cm}$ to $4.4 \mathrm{~cm})$, and huge type $(>4.5 \mathrm{~cm})$. In the neuroendoscopeassisted group, six cases belonged to the huge type, four cases belonged to the large type, and two cases belonged to the middle type. In the microscopic surgery group, four cases belonged to the huge type, five cases belonged to the large type, and three cases belonged to the middle type. For basilar artery circumvolution, the neuroendoscope-assisted group had five cases, whereas the microscopic surgery group had six cases. For brain stem edema, the neuroendoscope-assisted group had three cases, whereas the microscopic surgery group had two cases (comparisons of clinical data and MRI characteristics between the two groups are shown in Table I).

\section{Operative Procedure}

For the microscopic surgery group, the temporal and occipital transtentorial-crista petrosa approach and the suboccipital retrosigmoid suprameatal approach were respectively selected for the resection under a microscope according to the MRI classification of petroclival meningioma.

For the neuroendoscope-assisted group, the temporal and occipital transtentorial-crista petrosa approach and the suboccipital retrosigmoid suprameatal approach were respectively selected for the neuroendoscope-assisted microscopic resection according to the MRI classification of petroclival meningioma. For the "dead space" observed intraoperatively under the microscope, a neuroendoscope with $0^{\circ}$ or $30^{\circ}$ angulation was employed. If no residual tumor was found in the "dead space," the neuroendoscope was not used temporarily. If residual tumors were found in the "dead space," the blocked crista petrosa or tubercle on the internal auditory canal was further abraded to cut off tumors under the microscope as far as possible. If the surgeon thought that the tumors were fully cut off under the microscope, then the "dead space" was observed continuously under the neuroendoscope to check if total resection of tumors was indeed achieved. If the surgeon thought that only subtotal or most resection was conducted on the tumors under the microscope, then the "dead space" was observed continuously under the neuroendoscope to check for other tumors that could be removed (Figure 1A, B). 
Table I: Comparison of the Clinical Data Between Groups

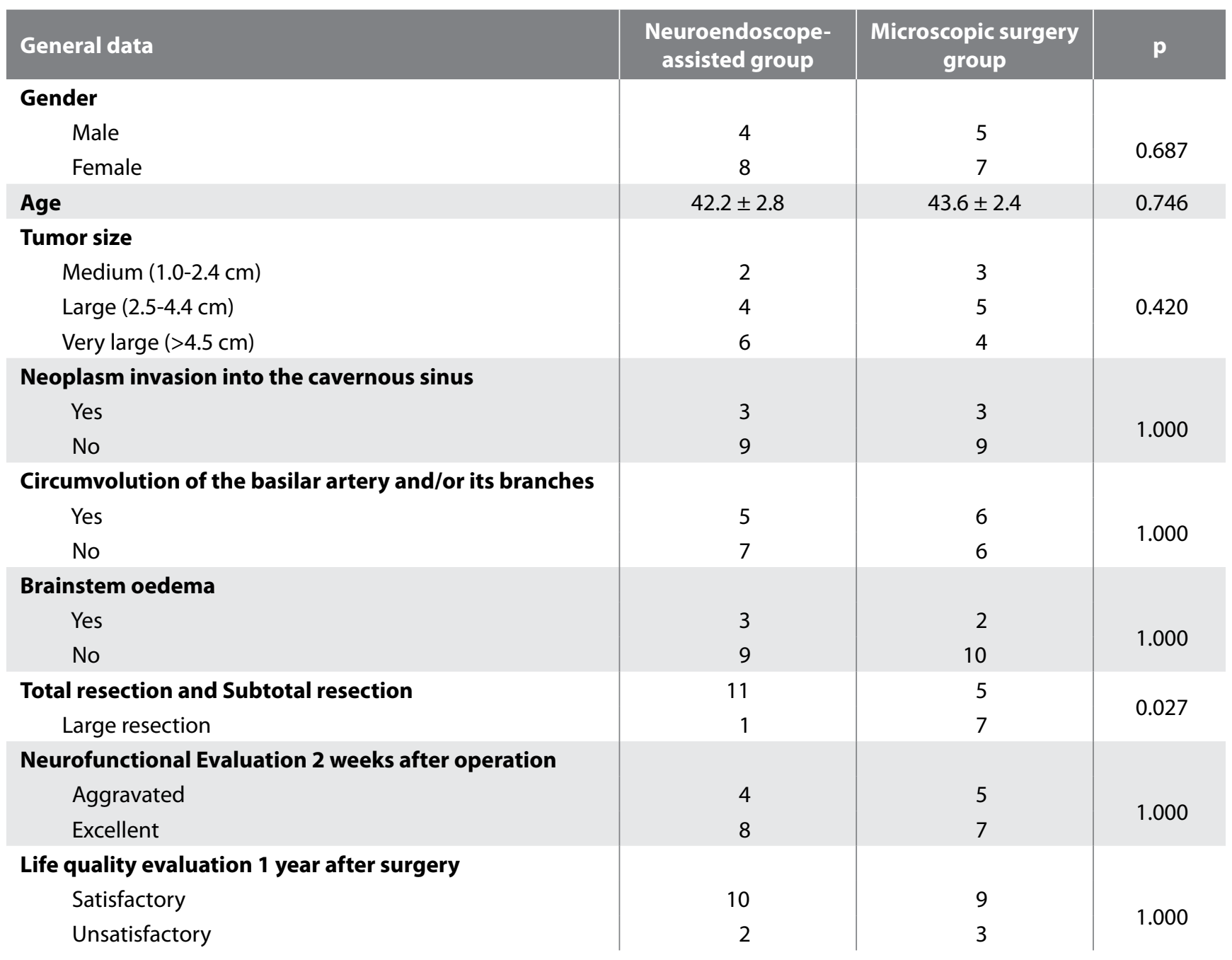
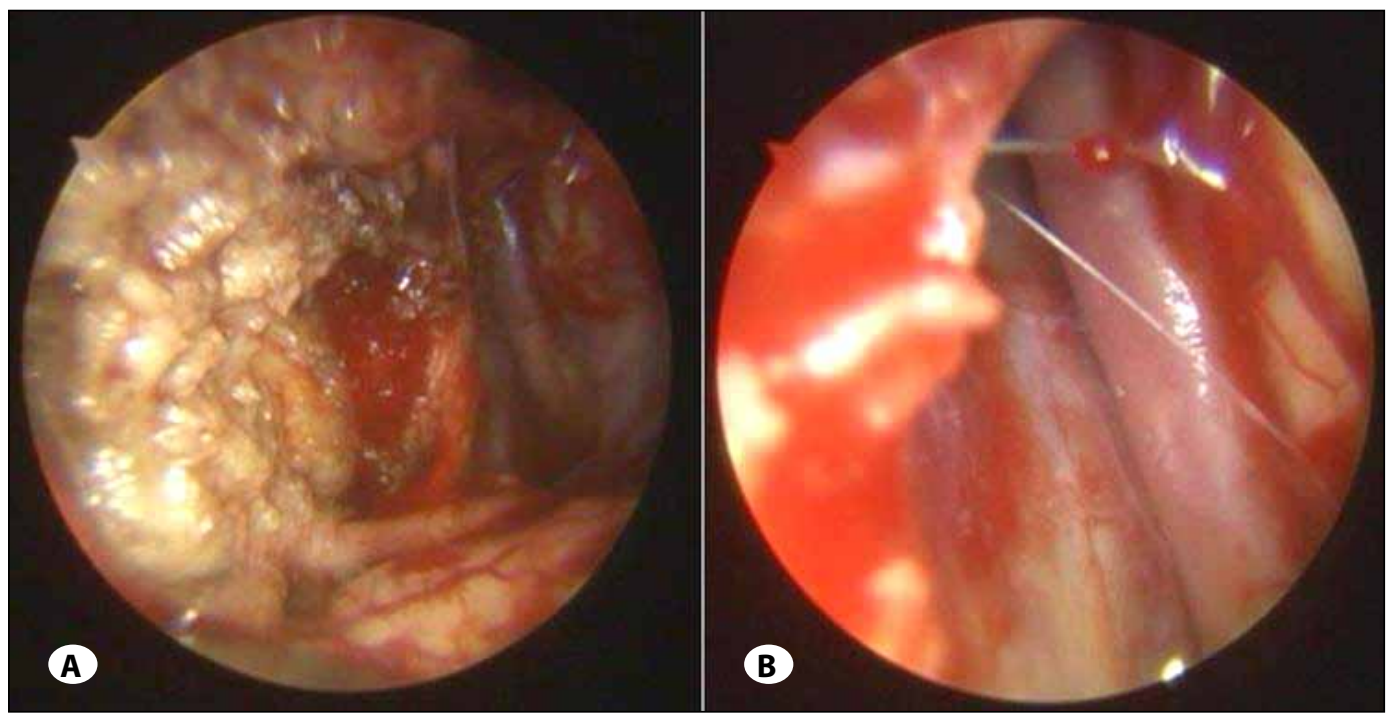

Figure 1:

A) Observation under the neuroendoscope after most resection of tumor; B) Basilar artery observed under the neuroendoscope after total resection of tumor. 


\section{Electrophysiological Monitoring of Cranial Nerves}

The operative-side trifacial, facial, and posterior cranial nerves were monitored during the operation. We evaluated 17 cases after 2007 in this study.

\section{Tumor Resection Criteria}

1) Total resection: $100 \%$ of the tumor body and tumor capsule were removed, 2) subtotal resection: over $90 \%$ of the tumor body was removed, 3) most resection: $60 \%$ to $90 \%$ of the tumor body was removed, and 4) partial resection: less than $60 \%$ of the tumor body was removed.

The judgment methods used were subjective judgment (i.e., written records of the surgeon after surgery) and objective judgment (i.e., postoperative head-imaging examination such as computed tomography scan and MRI).

\section{Clinical Evaluation Criteria}

Karnofsky performance status (KPS) score: For each patient with petroclival meningioma, KPS scoring was conducted before the operation and two weeks after the operation (based on the description of the patient). For nerve function evaluation indicators, "good" indicates that the KPS score at two weeks after the operation was more than (better) or equal to that before the operation, whereas "deteriorated" indicates that the KPS score two weeks after operation was less than that before the operation.

Glasgow outcome scale (GOS) prognosis score: For each patient with petroclival meningioma, postoperative GOS scoring was conducted (by phone or outpatient follow-up) for one year. For the evaluation indicator, "satisfactory" indicates that the GOS score of the survival quality of the patient at one year postoperatively was not less than 4 points (good survival quality), whereas "unsatisfactory" indicates that the GOS score of the survival quality of the patient at one year postoperatively was less than 4 points (bad survival quality).

\section{Statistical Analysis}

All data were processed using SPSS Statistics 17.0.1 software. The enumeration data sample size was less than 40 , and the chi-square exact probability test was conducted. If one-tailed $p<0.05$, then the difference was statistically significant.

\section{RESULTS}

\section{Comparison of Clinical Data}

Statistical analysis showed a balance between the neuroendoscope-assisted group and the microscopic surgery group (all $p>0.05$, Table I). Thus, a comparative analysis was feasible.

\section{Operation Situations}

In the neuroendoscope-assisted group, neuroendoscopeassisted microscopic resection was conducted for all 12 patients with petroclival meningioma. In four of the six cases in which the patients had undergone total resection of petroclival meningioma, the surgeon thought that the tumors could be completely removed during surgery. The "dead space" was continuously observed under the neuroendoscope to find residual tumors, and the petrous bone was further abraded to expose the "dead space" for total resection of tumors. During surgery, the surgeon thought that only most resection could be conducted for five cases of petroclival meningioma. However, with the assistance of neuroendoscopy, subtotal resection was achieved. In one case in which the patient had undergone most resection because of tumors wrapped around the basilar artery, no removable tumor was found under the neuroendoscope, and thus, the resection was stopped. The intraoperative utilization rate of neuroendoscopy was $9 / 12$ (75\%).

The tumor resection situations of the neuroendoscopeassisted group and the microscopic surgery group were as follows. For the neuroendoscope-assisted group, 6, 5, and 1 cases were respectively subjected to total resection (Figure 2A,B), subtotal resection, and most resection. For the

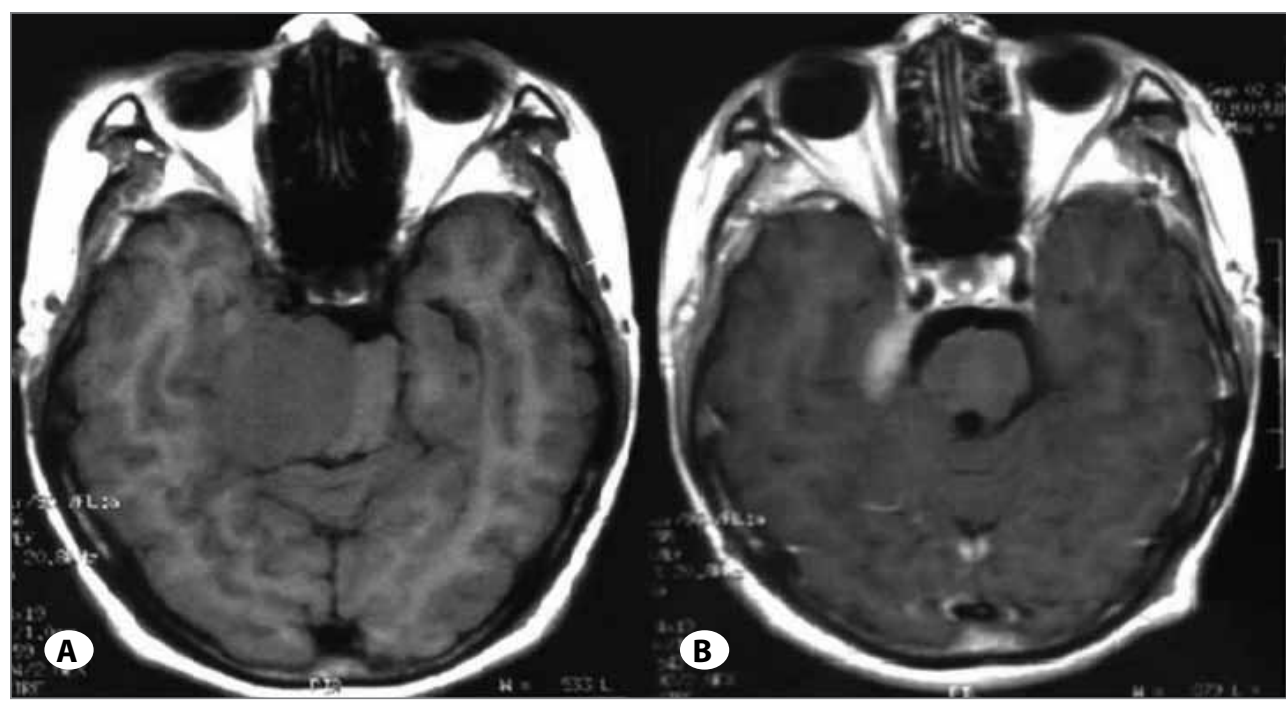

Figure 2: A) Preoperative MRI manifestations of right petroclival meningioma; B) Postoperative MRI manifestations of right petroclival meningioma. 
microscopic surgery group, 2, 3, and 7 cases were respectively subjected to total resection, subtotal resection, and most resection (Table II). No patient died in this study.

Statistical analysis showed no difference in the resection extent of petroclival meningioma between the two groups ( $p=0.156)$, thus suggesting that the extent of petroclival meningioma resection in the neuroendoscope-assisted group was not different from than in the microscopic surgery group.

To investigate the effect of different operative procedures on the total resection rate of petroclival meningioma, we integrated subtotal and most resection into incomplete resection (Table III).

Statistical analysis showed no difference in the total resection rates of tumors between the two groups ( $p=0.193$ ), thus suggesting that the total resection rate of petroclival meningioma in the neuroendoscope-assisted group did not increase.

We integrated total and subtotal resection into complete resection for comparison with most resection. We also investigated whether a difference exists in the complete resection rates of petroclival meningioma (including total and subtotal resection) between the neuroendoscope-assisted group and the microscopic surgery group (Table IV).

Statistical analysis showed a significant difference in the complete resection rates of petroclival meningioma between the two groups $(p=0.027)$. The complete resection rate of petroclival meningioma in the neuroendoscope-assisted group $(11 / 12,92 \%)$ was higher than that in the microscopic surgery group $(5 / 12,42 \%)$. Compared with microscopic surgery, neuroendoscope-assisted microscopic surgery can increase the total and subtotal resection rates of petroclival meningioma.

\section{Pathological Results}

For the neuroendoscope-assisted group, 4, 4, 4, and 2 cases were respectively of meningothelial, fibrous, grit, and mixed types. For the microscopic surgery group, 5, 4, and 3 cases were respectively of meningothelial, fibrous, and mixed types.

\section{Evaluating Nerve Functions}

At two weeks postoperatively for the neuroendoscopeassisted group, the nerve functions in 8 cases (67\%) were good, whereas those in 4 cases (33\%) deteriorated. For the microscopic surgery group, the nerve functions in 7 cases $(58 \%)$ were good, whereas those in 5 cases $(42 \%)$ deteriorated (Table V).

Statistical analysis showed no difference in postoperative nerve functions between the two groups, thus suggesting that the incidence of postoperative neurological dysfunction among patients in the neuroendoscope-assisted group $(4 / 12,33 \%)$ was comparable with that among patients in the microscopic surgery group $(5 / 12,42 \%)$, and that no difference was detected ( $p=0.027$ ). Neuroendoscope-assisted surgery did not increase the short-term complications of the operation.

\section{Evaluating Survival Quality}

At one year postoperatively for the neuroendoscope-assisted group, the survival quality in 10 cases (83\%) was good, whereas that in 2 cases (17\%) was bad. For the microscopic

Table II: Comparison of Tumor Resection Between Groups

\begin{tabular}{l|c|c|c|}
\multirow{2}{*}{ Group } & \multicolumn{3}{|c}{ Tumor resection } \\
\cline { 2 - 4 } & $\begin{array}{c}\text { Total } \\
\text { resection }\end{array}$ & $\begin{array}{c}\text { Subtotal } \\
\text { resection }\end{array}$ & $\begin{array}{c}\text { Large } \\
\text { resection }\end{array}$ \\
$\begin{array}{l}\text { Neuroendoscope- } \\
\text { assisted }\end{array}$ & 6 & 5 & 1 \\
$\begin{array}{l}\text { Microscopic } \\
\text { surgery }\end{array}$ & 2 & 3 & 7 \\
p & & 0.156 &
\end{tabular}

Table III: Comparison of the Total Resection Rates Between Groups

\begin{tabular}{|l|c|c|}
\multirow{2}{*}{ Group } & \multicolumn{2}{|c}{ Tumor resection } \\
\cline { 2 - 3 } & $\begin{array}{c}\text { Total } \\
\text { resection }\end{array}$ & $\begin{array}{r}\text { Non-total } \\
\text { resection }\end{array}$ \\
\hline Neuroendoscope-assisted & 6 & 6 \\
\hline Microscopic surgery & 2 & 10 \\
\hline $\mathrm{p}$ & \multicolumn{3}{|c|}{0.193} \\
\hline
\end{tabular}

Table IV: Comparison of the "Total Resection" Rates Between Groups

\begin{tabular}{|l|c|c|}
\multirow{2}{*}{ Group } & \multicolumn{2}{|c}{ Tumor resection } \\
\cline { 2 - 3 } & $\begin{array}{c}\text { Total } \\
\text { resection }\end{array}$ & $\begin{array}{c}\text { Large } \\
\text { resection }\end{array}$ \\
\hline Neuroendoscope-assisted & 11 & 1 \\
\hline Microscopic surgery & 5 & 7 \\
\hline $\mathrm{p}$ & \multicolumn{2}{|c|}{0.027} \\
\hline
\end{tabular}

The case number of "total resection" is the sum of the numbers of tumor total resection and subtotal resection.

Table V: Comparison of the Postoperative Neurofunctions Between Groups

\begin{tabular}{l|c|c|}
\multirow{2}{*}{ Group } & \multicolumn{2}{|c|}{$\begin{array}{c}\text { Neurofunctional evaluation } \\
\text { 2 weeks after operation }\end{array}$} \\
\cline { 2 - 3 } & Aggravated & Excellent \\
\hline Neuroendoscope-assisted & 4 & 8 \\
\hline Microscopic surgery & 5 & 7 \\
\hline p & \multicolumn{2}{|c|}{1.000} \\
\end{tabular}


Table VI: Comparison of the Postoperative Life Quality Between Groups

\begin{tabular}{|l|c|c|}
\multirow{2}{*}{ Group } & \multicolumn{2}{c}{$\begin{array}{r}\text { Life quality evaluation } \\
1 \text { year after operation }\end{array}$} \\
\cline { 2 - 3 } & Satisfactory & Unsatisfactory \\
\hline Neuroendoscope-assisted & 10 & 2 \\
\hline Microscopic surgery & 9 & 3 \\
\hline P & \multicolumn{2}{|c|}{1.000} \\
\hline
\end{tabular}

surgery group, the survival quality in 9 cases (75\%) was good, whereas that in 3 cases (25\%) was bad (Table VI).

Statistical analysis showed no difference for postoperative survival quality between the two groups, thus suggesting that the good survival quality rate of the neuroendoscopeassisted group at one year postoperative (10/12, 83\%) was comparable with that of the microscopic surgery group (9/12, $75 \%)(p=0.027)$. Neuroendoscope-assisted surgery did not increase the long-term complications of the operation.

\section{Follow-up}

All 24 cases were followed up for more than one year. In six cases that had undergone most resection, four patients received gamma knife treatment after their operation, and no tumor recurrence was observed.

\section{DISCUSSION}

The petroclival region includes the petrous bone, clivus, and nearby III to VI pairs of cranial nerves and great vessels. This region has been the most active region in skull base surgery in recent years. Castellano and Ruggiero (7) classified posterior fossa meningioma into five types (cerebellar convexity, tentorium cerebelli, posterior petrous bone surface, clivus, and foramen magnum region) according to autopsy findings in 1953. Yasargil et al. classified posterior fossa meningioma into five types (clivus, petrous bone-clivus region, sphenopetroclival region, foramina magnum, and cerebellopontine angle) according to surgical findings in 1980, and first proposed the concept of "petroclival region" (20). Aziz et al. limited the range of the petroclival region to the region in front of the dorsum sellae (1); at the back of the anterior margin of the foramen magnum; and lateral to the trifacial, facial, and vestibulocochlear nerves. Then, the authors divided this region into upper, middle, and lower zones in terms of internal acoustic canal and superior margin lines of the jugular foramen.

Microsurgical operation is the preferred treatment method for petroclival meningioma. Two minimally invasive operation approaches are available for petroclival meningioma, namely, the temporal and occipital transtentorial-crista petrosa approach and the suboccipital retrosigmoid suprameatal approach. Two approaches are also available for removing the petrous apex, internal auditory canal crest, and its lateral petrous bone crest to form the "bongrace-like" structure. The aforementioned structure is appropriately abraded by the lower dura mater to increase exposure of the posterior fossa surface of the petrous bone. However, abrading the petrous bone increases the possibility of inflicting injuries to the cochlea, genu of facial nerve, horizontal segment of the petrous internal carotid artery, and other important structures. Thus, a certain risk is involved in these approaches. If exposure is inadequate, tumors are easily left out. Ichimura et al. reported 91 cases of petroclival meningioma and found that $70.3 \%$ of tumors invaded Meckel's cavity (11). This cavity is often the postoperative residual site of tumors, thus causing tumor recurrence.

To reduce intraoperative injuries caused by abrading the petrous bone, neuroendoscope-assisted surgery was used in the present study to increase intraoperative exposure, and thus, reduce injuries and increase the total resection rate of tumors.

In this study, 12 patients with petroclival meningioma had undergone neuroendoscope-assisted microscopic resection. Among the six cases of patients who had undergone total resection of petroclival meningioma, the surgeon thought that the tumors in four cases could be completely removed during the operation. The "dead space" was continuously observed under the neuroendoscope to find residual tumors, and the petrous bone was further abraded to expose the "dead space" to ensure total resection of tumors. During the operation, the surgeon thought that only most resection had been conducted for five cases of petroclival meningioma. However, subtotal resection was achieved with the assistance of neuroendoscopy. In one case in which the patient had undergone most resection because of tumors wrapped around the basilar artery, no removable tumor was found under the neuroendoscope, and thus, resection was stopped. The intraoperative utilization rate of neuroendoscopy was 9/12 (75\%). Neuroendoscopy can help significantly increase the resection extent of the tumor and can assist microscopic surgery in increasing the total resection rate of petroclival meningioma.

For the neuroendoscope-assisted group, 6, 5, and 1 cases were respectively subjected to total resection, subtotal resection, and most resection. For the microscopic surgery group, 4, 3, and 5 cases were respectively subjected to total resection, subtotal resection, and most resection. No patient died in this study. Based on the comparison of the total resection rates between the two groups, no difference was found between the neuroendoscope-assisted and microscopic surgery groups, which is significantly different from that in intraoperative situations. We believe that total resection of petroclival meningioma is associated with risk factors such as the tumor invading the cavernous sinus, the tumor wrapping the basilar artery and its branches, and tumor damaging the arachnoid. These risk factors can cause brain stem edema and limit tumor resection. In such cases, even neuroendoscopy cannot increase the total resection rate. 
Thus, subtotal resection of the tumor should be conducted to increase the survival quality of the patient after petroclival meningioma resection. We integrated total and subtotal resection into complete resection for comparison with most resection. Statistical analysis showed that the "complete rate" of petroclival meningioma in the neuroendoscopeassisted group $(11 / 12,92 \%)$ was higher than that in the microscopic surgery group $(7 / 12,58 \%)$, thus suggesting that neuroendoscopy can increase the total and subtotal resection rates of petroclival meningioma.

Given the deep location of petroclival meningioma, important neural and vascular structures such as the brain stem, cavernous sinus, and internal auditory canal surround this tumor. Petroclival meningioma often crosses the middle and posterior cranial fossa because of invasive tumor growth. Thus, the surgeon usually cannot consider all these aspects if skull base surgery is selected. When the temporal and occipital transtentorial-crista petrosa approach is selected to treat middle cranial fossa-predominant petroclival meningioma, the surgeon should be cautious when working in the posterior cranial fossa part of the tumor. When the suboccipital retrosigmoid suprameatal approach is selected to cut off the posterior cranial fossa-predominant petroclival meningioma, the surgeon should be relatively conservative when working in the middle cranial fossa part of the tumor. Although abrading nodes on the petrous bone crest and internal auditory canal increases tumor exposure, these nodes are full of risks. Neuroendoscopy has imaging features that can provide wide angulation, good lighting, and local amplification functions for examining deep anatomical structures (19). Neuroendoscopy can also enable observation of the posterior cranial fossa (or middle cranial fossa) at the middle cranial fossa (or posterior cranial fossa). Thus, neuroendoscopy can achieve a field of vision that cannot be observed through microscopy, without increasing craniotomy range and skull base sclerotin abrasion. When residual tumors are found in the "dead space" under the microscope, the surgeon can adjust the angle of the microscope or abrade skull base sclerotin to increase exposure and continue removing tumors. Thus, the total rate of tumor removal is increased. If a neuroendoscope is used to assist in observing the "dead space" under the microscope and no residual tumor is found in the "dead space," then skull base sclerotin does not need to be abraded or only needs to be slightly abraded. Thus, complications caused by abrading skull base sclerotin can be reduced.

At two weeks postoperatively, for the neuroendoscopeassisted group, the nerve functions of eight cases were good, whereas those of four cases deteriorated. For the microscopic surgery group, the nerve functions of seven cases were good, whereas those of five cases deteriorated. Statistical analysis showed no difference in postoperative nerve functions between the two groups, thus suggesting that the incidence of postoperative neurological dysfunction among patients in the neuroendoscope-assisted group was comparable with that among patients in the microscopic surgery group. Thus, neuroendoscope-assisted surgery did not increase short-term complications of the operation. At one year postoperatively, for the neuroendoscope-assisted group, the survival quality in ten cases was good, whereas that in two cases was bad. For the microscopic surgery group, the survival quality in nine cases was good, whereas that in three cases was bad. Statistical analysis showed no difference for postoperative survival quality between the two groups, thus suggesting that neuroendoscope-assisted surgery did not increase longterm complications of the operation.

Neuroendoscope-assisted surgery can increase the total resection rate of petroclival meningioma; however, whether a high incidence of complications will result remains unclear because of the increase in the total resection rate and the neuroendoscope itself. Although neuroendoscopy is used in an auxiliary manner during microscopic surgery, if a neuroendoscope is placed at the skull base for observations, it can cause certain injuries. However, the neuroendoscope used in this study (the temporal and occipital transtentorialcrista petrosa approach or the suboccipital retrosigmoid suprameatal approach) was used only after resection of the tumor body at the middle cranial fossa or posterior cranial fossa. After the tumor body at the middle cranial fossa or posterior cranial fossa is removed, a larger space will be formed to allow the neuroendoscope to go through nerves and vessels and enter the skull base. The surgeon must be skilled in operating a neuroendoscope to avoid unnecessary injuries. The surgeons in this study were all professionally trained in neuroendoscopy, and no iatrogenic injury because of misoperation occurred.

We found the following results for neuroendoscope-assisted microscopic resection of petroclival meningioma. 1) Initial observations with a neuroendoscope at $0^{\circ}$ angulation and then increasing the observation range to $30^{\circ}$ angulation (a skilled surgeon can directly apply the neuroendoscope at $30^{\circ}$ angulation) are feasible. 2) The neuroendoscope only has an auxiliary role in the resection of petroclival meningioma, and its main function is to assist in observing lesions and structures of the skull base, thus making up for the limitations of the optical principle of microscopy. However, an endoscope should not be used during a separation operation. Neuroendoscopy is useful in observing small intraoperative skull space and complex structures. However, important vessels and cranial nerves surround this region, and the endoscope can only account for a certain space. Moreover, compared with the three-dimensional panoramic view of a microscope, the two-dimensional image of a neuroendoscope lacks a sense of depth. Although tissue structures are clearly displayed, intraoperative surgical operation is more difficult. Surgeons who are unskilled in neuroendoscopic surgery may accidentally injure peripheral nerves and vessels. 3) A neuroendoscope is used only after the tumor body at the middle cranial fossa or posterior cranial fossa is removed, and before skull base sclerotin is abraded. Thus, neuroendoscopic observations can identify the location and size of residual tumors. The locations of nerves and vessels around tumors 
can point the surgeon toward the correct direction and the appropriate amount of skull base sclerotin abrasion. Thus, avoiding excessive abrasion of skull base sclerotin and simultaneously reducing injuries caused by abrading direction errors are possible.

\section{CONCLUSION}

Neuroendoscope-assisted microscopic resection of petroclival meningioma can increase the extent of intraoperative resection of tumors, as well as the total and subtotal resection rates of the tumor. This approach does not increase postoperative short-term and long-term complications.

\section{ACKNOWLEDGEMENTS}

This study was supported by Natural Science Foundation of the Xinjiang Uygur Autonomous Region (2012211A079).

\section{REFERENCES}

1. Abdel Aziz KM, Sanan A, van Loveren HR, Tew JM Jr, Keller JT, Pensak ML: Petroclival meningiomas: Predictive parameters for transpetrosal approache. Neurosurgery 47: $139-152,2000$

2. Alfieri A, Jho HD: Endoscopic endonasal cavernous sinus surgery: An anatomic study. Neurosurgery 48: 827-837, 2001

3. Alfieri A, Jho HD: Endoscopic endonasal approaches to the cavernous sinus: Surgical approaches. Neurosurgery 49: 357-362, 2001

4. Bambakidis NC, Kakarla UK, Kim LJ, Nakaji P, Porter RW, Daspit CP, Spetzler RF: Evolution of surgical approaches in the treatment petroclival meningiomas: A retrospective review. Neurosurgery 62 Suppl 6: 1182-1191, 2008

5. Barnett SL, Ambrosio AL, Agazzi S, van Loveren HR: Petroclival and Upper Clival Meningiomas III: Combined Anterior and Posterior Approach Meningiomas. Lee JH, London: Springer, 2009: 425-432

6. Cappabianca P, Cinalli G, Gangemi M, Brunori A, Cavallo LM, de Divitiis E, Decq P, Delitala A, Di Rocco F, Frazee J, Godano U, Grotenhuis A, Longatti P, Mascari C, Nishihara T, Oi S, Rekate H, Schroeder HW, Souweidane MM, Spennato P, Tamburrini G, Teo C, Warf B, Zymberg ST: Application of neuroendoscopy to intraventricular lesions. Neurosurgery 62 Suppl 2: 575-597, 2008

7. Castellano F, Ruggiero G: Meningiomas of the posterior fossa. Acta Radiol 104: 1-177, 1953

8. Cavallo LM, Cappabianca P, Galzio R, laconetta G, de Divitiis E, Tschabitscher M: Endoscopic transnasal approach to the cavernous sinus versus transcranial route: Anatomic study. Neurosurgery 56: 379-389, 2005
9. Dewaele F, Kalmar AF, Van Canneyt K, Vereecke H, Absalom A, Caemaert J, Struys MM, Van Roost D: Pressure monitoring during neuroendoscopy: New insights. Br J Anaesh 107: 218-224, 2011

10. Erkmen K, Pravdenkova S, Al-Mefty O: Surgical management of petroclival meningiomas: Factors determining the choice of approach. Neurosurg Focus 19: E7, 2005

11. Ichimura S, Kawase T, Onozuka S, Yoshida K, Ohira T: Four subtypes of petroclival meningiomas: Differences in symptoms and operative findings using the anterior transpetrosal approach. Acta Neurochir (Wien) 150: 637-645, 2008

12. Kuniki E, Adriana T, Satoshi $Y$, Toshinori M, Takafumi M, et al. Feasibility and limitations of the retrosigmoid and presigmoid approaches combined with the anterior petrosal approach to meningiomas in the petroclival area. Neurosurg Q 23:7-12,2013

13. Li D, Hao SY, Wang L, Tang J, Xiao XR, Zhou H, Jia GJ, Wu Z, Zhang LW, Zhang JT: Surgical management and outcomes of petroclival meningiomas: A single-center case series of 259 patients. Acta Neurochir 155:1367-1383, 2013

14. Little KM, Friedman AH, Sampson JH, Wanibuchi M, Fukushima $\mathrm{T}$ :Surgical management of petroclival meningiomas: Defining resection goals based on risk of neurological morbidity and tumor recurrence rates in 137 patients. Neurosurgery 56: 546-559, 2005

15. Mathiesen T, Gerlich A, Kihlström L, Svensson M, BaggerSjöbäck D: Effects of using combined transpetrosal surgical approaches to treat petroclival meningiomas. Neurosurgery 60: 982-992, 2007

16. Natarajan SK, Sekhar LN, Schessel D, Morita A: Petroclival meningiomas: Multimodality treatment and outcomes at long-term follow up. Neurosurgery 60: 965-979; discussion: 979-981, 2007

17. Samii M, Gerganov VM: Surgery of extra-axial tumors of the cerebral base. Neurosurgery 62: 1153-1166, discussion 11661158,2008

18. Samii M, Gerganov VM: Petroclival meningiomas: Quo vadis. World Neurosurg 75: 424, 2011

19. Taniguchi M, Perneczky A: Subtemporal keyhole approach to the suprasellar and petroclival region: Microanatomic considerations and clinical application. Neurosurgery 41: 592-601, 1997

20. Yasargil MG, Mortara RW, Curie M: Meningiomas of basal posterior cranial fossa. Adv Tech Stand Neurosurg 7:1-15, 1980

21. Zada G, Liu C, Apuzzo ML: "Through the looking glass": Optical physics issues, and the evolution of neuroendosvopy. World Neurosurg 23: 12-14, 2011 